\title{
Interseções antropológicas na saúde mental: dos regimes de verdade naturalistas à espessura biopsicossociocultural do adoecimento mental
}

Mônica de Oliveira Nunes ${ }^{1}$

NUNES, M.O. Anthropological intersections in mental health: from naturalistic regimes of truth to the biopsychosociocultural thickness of mental illness. Interface - Comunic., Saude, Educ., v.16, n.43, p.903-15, out./dez. 2012.

In contemporary psychiatry, a hegemonic transnational project centered on naturalistic discourse about mental illness disseminates a regime of truth based on explanation of its physiopathology and on mastery of its treatment. Despite this diffusion, some studies have demonstrated how this discourse has different repercussions in specific cultural contexts, showing socioanthropological modulations of biotherapeutics in people's material state of health and the uses and meanings attributed to diagnoses. A second group of studies has analyzed historical constructions of mental illnesses and has defined cultural polarities placing value on certain types of behavior as either perverse or virtuous. A third group has analyzed the uses of cultural resources as a means of negotiating experiences of otherness and has defined cultural contexts that are more open to difference. This article makes a review of these three perspectives, putting emphasis on intersections between history, culture, society and biology that put mental illnesses into context.

Keywords: Anthropology medical. Mental health. Drug utilization. Social construction. Otherness.
Na psiquiatria contemporânea, um projeto hegemônico transnacional centrado em um discurso naturalista acerca das doenças mentais propaga um regime de verdade ancorado na proposta de explicação da sua fisiopatologia e no domínio do seu tratamento. A despeito da sua difusão, um grupo de estudos demonstra como esse discurso repercute diferentemente em contextos culturais específicos, evidenciando modulações socioantropológicas das bioterapêuticas no estado de saúde concreto das pessoas e dos usos e sentidos atribuídos a diagnósticos. Um segundo grupo analisa construções históricas de doenças mentais, definindo polaridades culturais que valorizam enquanto viciosos ou virtuosos determinados comportamentos. Um terceiro grupo analisa usos de recursos culturais de modo a negociar experiências de alteridade, definindo contextos culturais mais abertos à diferença. Este artigo faz uma revisão dessas três perspectivas, enfatizando interseções entre história, cultura, sociedade e biologia na ancoragem das doenças mentais.

Palavras-chave: Antropologia médica. Doença mental. Uso de medicamentos. Construção social. Alteridade.
1 Departamento de Saúde Coletiva, Instituto de Saúde Coletiva Universidade Federal da Bahia. Rua Basílio da Gama, s/n, Campus Universitário do Canela. Salvador, BA, Brasil. 41.10-140 


\section{Introdução}

Observa-se, na psiquiatria contemporânea, um projeto hegemônico transnacional centrado sobre um discurso naturalista acerca das doenças e estados mentais (Jeannerod, 2001). Este propaga um regime de verdade ancorado na proposta de explicação da fisiopatologia dessas doenças, no domínio do seu tratamento e no controle do seu sofrimento. À primeira vista, é inegável reconhecer que esse discurso se sustenta nos benefícios que a perspectiva neurobiológica tem aportado à psiquiatria, uma vez que, aliados aos avanços observados pelos efeitos psicofarmacológicos de controle de sintomas graves, surgem os efeitos sociais positivos desse discurso e prática. Dentre estes, valem ser destacados: a contenção da insegurança e a isenção da culpa de pacientes e familiares, por um mecanismo de genetização e de biologização dos sintomas; a esperança da gestão da incerteza e da falta de esperança de doenças tão complexas quanto dolorosas; além da produção de pontos de ancoragem, ou seja, da possibilidade de, uma vez exteriorizadas as responsabilidades sociopsicológicas na produção do adoecimento, abrir espaço para a relação terapêutica e para o trabalho sobre as relações.

Esses efeitos promissores, no entanto, frequentemente têm sido hiperinterpretados em um discurso cientificista mistificador que aparece, constantemente, na mídia, nas indústrias farmacêuticas, ou nos discursos de familiares ávidos por encontrarem alívio para o sofrimento de seus doentes. Grande parte desta mistificação reside, especialmente, nas armadilhas da própria perspectiva teórica ou ideológica da psiquiatria biológica. Dentre estas, salientam-se: o reducionismo ao tratamento exclusivamente medicamentoso, a mitificação das moléculas, a linearidade da relação causa-efeito entre substância e comportamento, a leitura dos sintomas a partir de uma perspectiva impessoal e invariável, observada nos manuais estatísticos das doenças mentais, além da marginalização das interpretações subjetivas e da ancoragem sociocultural dos processos de adoecimento.

A despeito da grande difusão desses discursos, um número crescente de estudos tem demonstrado que é muito difícil (se não impossível), e especialmente improdutiva, a separação entre os domínios biológico, psíquico e social quando se quer verificar os efeitos das neurociências fora dos laboratórios, ou seja, das bioterapêuticas no estado de saúde concreto das pessoas. Assim, estudos etnográficos têm observado como esse discurso e a prática biologicista da psiquiatria repercutem diferentemente em contextos culturais específicos, identificando suas modulações socioantropológicas. Estes evidenciam clínicas afetadas por processos sócio-históricos, ciências socialmente (e economicamente) construídas e biologias que ganham colorações particulares e respondem diferentemente de acordo com contextos culturais distintos. De fato, os estudos socioantropológicos têm produzido um acúmulo expressivo de resultados que colocam em questão, relativizam, ou até refutam algumas verdades biomédicas acerca das doenças mentais.

No presente artigo, a partir de uma revisão da literatura internacional, apresentaremos três vertentes antropológicas e históricas e as suas diferentes perspectivas de ancoragem sociocultural das doenças mentais, privilegiando os resultados de seus estudos empíricos. O primeiro grupo revela que as doenças mentais guardam uma historicidade forte, descrevendo doenças mentais em mutação (Ehrenberg, Lovell, 2001). Estas são configuradas a partir de valores, significados e dinâmicas sociais dominantes do seu tempo, analisando os processos de produção de novas nosologias psiquiátricas (Young, 2001) e até identificando doenças de aparecimento florido e fim abrupto (Hacking, 1998). Um segundo conjunto de estudos tem se centrado nos processos de estandardização internacional de diagnósticos psiquiátricos e na influência das tradições terapêuticas, dos processos clínicos e dos contextos econômicos sobre as construções e os usos desses diagnósticos. Por fim, um terceiro grupo de investigações tem examinado a fina participação dos processos sociais e culturais no modo como pessoas, que apresentam doenças psiquiátricas graves, se servem de recursos simbólicos e psicossociais nas suas experiências cotidianas desses fenômenos (Good, 2007; Nunes, 1999; Corin, Lauzon, 1992). Esse grupo destaca o agenciamento dos sujeitos na forma de produzir, bricolar e reinterpretar recursos culturais, de modo a valorizar ou fazer sobreviver aspectos fundamentais da alteridade. 


\section{Transformações históricas e atmosferas culturais na tessitura das formas de adoecimento}

Um grupo de estudos fundamentais na reflexão provocada a partir da virada biológica da psiquiatria tem sido o que examina a relação entre doença mental e história. Alguns analisam as razões que levariam ao aparecimento eventual de certas doenças mentais por um curto período histórico. Aqui, temos o trabalho paradigmático de lan Hacking (1998), onde ele descreve o caso de Albert Dadas, de origem francesa, conhecido por suas notórias expedições por países longínquos, sendo a primeira pessoa a ser diagnosticada como um viajante louco. Esses estados de fuga, apresentados por viajantes em estados de consciência alterada, duraram entre finais do século XIX e o início do século XX. Segundo o autor, a combinação, naquele período, de um turismo muito em voga com o medo dos crimes associados à vagabundagem pode ter constituído o nicho ecológico que fez desses loucos, que vagavam de um país a outro, o alvo de constituição de uma doença médica particular. Com isso, Hacking apresenta o conceito de polaridade cultural, indicando-o como um dos elementos-chave para se compreenderem as doenças mentais transitórias. Este conceito definiria fenômenos sociais muito prevalentes, mas, ao mesmo tempo, opostos na sua significação cultural: um virtuoso e outro vicioso (virtuous and vicious). Tomando ainda outras doenças mentais epidêmicas, o autor tenta diferenciar afecções «reais» de artefatos culturais, defendendo que a 'realidade' de uma doença só encontra resposta se explorado seu nicho ecológico, uma espécie de substância ética de uma cultura, que favorece a sua emergência.

O trabalho de Allan Young (2001) segue este argumento, mostrando que o transtorno de estresse pós-traumático se constitui, na clínica contemporânea, como uma nova maneira de trabalhar sobre a infelicidade moral. Ele descreve em que circunstâncias de uma organização sanitária voltada para excombatentes de guerra do Vietnam esse transtorno emerge e mobiliza um extraordinário programa de pesquisas neurofisiológicas em torno de si, o que, por sua vez, também justifica a sua manutenção. Para Young, esse transtorno se inscreve na intercessão de pesquisas biológicas e de interesses sociais, econômicos e políticos. A novidade se encontra especialmente na constituição de um tipo particular de paciente que é pura vítima, condição justificada por explicações médicas que negam qualquer participação de desejos, conflitos e, mesmo, do inconsciente na sua produção. Analisando as condições de produção dessa doença, Young se questiona se ela terá ou não um futuro.

Tornar-se ou não uma doença transitória, só a história pode dizer; no entanto, independentemente de uma eventual circunscrição restrita no tempo, todas as doenças mentais têm uma historicidade, na perspectiva em que elas refletem a atmosfera cultural de um tempo. É nessa linha que Davis (2008) analisa a relação entre a obsessão, enquanto traço cultural positivo, e a neurose obsessiva, mais particularmente o transtorno obsessivo-compulsivo, tomando-as como polaridades culturais. Relaciona, na primeira metade do século XIX, na cultura popular, uma tendência a premiar o ideal das paixões obsessivas e a capacidade obsessiva de seguir um objetivo na vida. Vai até o extremo, encontrado no século XX, onde a focalização, a minúcia e a repetição tornam-se traços extremamente requeridos, observados, por exemplo: na necessidade de checar e-mails em períodos mínimos de tempo, na adição sexual, ou na estética obsessiva das artes. Davis sugere que o aumento expressivo do diagnóstico de obsessão na modernidade se relaciona com a presença desse traço obsessivo em uma cultura que, em face das suas mudanças tecnológicas, passa a supervalorizar comportamentos rotinizados e atenções estreitamente focalizadas. Este aumento atinge o seu ápice nos últimos trinta anos, com a sua conformação no diagnóstico de transtorno obsessivo-compulsivo (TOC). Não negando a importância de buscar as bases neuroquímicas dessas doenças, ele argumenta que oferecer aos médicos e aos pacientes a possibilidade de considerá-las na integralidade de seus aspectos sociais, culturais, históricos e políticos aumentaria a chance de resultados favoráveis para os seus tratamentos.

Observa-se, portanto, que as polaridades culturais inscrevem e significam sintomas em valores culturais historicizados. Garantem-Ihes, assim, uma compreensibilidade coletiva, ao mesmo tempo em que permitem jogos intersubjetivos empreendidos entre as produções diagnósticas, seus usos e os interesses desses usos. Processos históricos, dinâmicas sociais, relações de poder e trajetórias subjetivas se interinfluenciam na definição do destino, incerto e imprevisível, dado aos diagnósticos tanto em seu 
tempo histórico quanto biográfico. Estas interações complexas dificultam previsões lineares, linhas de continuidade e relações de determinação ligadas a doenças específicas. A partir dessas constatações, autores vão tomar por objeto os processos de transformação de doenças de base afetivo-emocional em desordens biológicas. Analisam as mudanças históricas que favorecem o esteio social dessas transformações, ao mesmo tempo em que instauram uma ruptura semântica entre as mesmas. Concluem que novas entidades são produzidas, embora uma estratégia naturalizadora instaure uma linha de continuidade histórica, garantida por um mito de origem que afirma que elas sempre existiram, embora fossem subdiagnosticadas.

Pierre-Henri Castel (2008), por exemplo, vai estudar as origens da neurose obsessiva, relacionando-a ao crescimento do protestantismo na sociedade alemã. Religião cujo etos está referido à ideia de que a graça deve preceder as ações, ela inscreve nestas todo tipo de impedimentos, dúvidas e indecisões. A neurose obsessiva seria uma doença da dúvida e surge em um momento onde a culpabilidade se torna um organizador moral no centro da economia psíquica. Transformações históricas vêm ligadas a ideais de construção de pessoa e, com essas, diferentes formas de individualismo produzem formas distintas de objetivação da mente e de afetação psíquica. Segundo Castel, mudanças históricas nos fins do século XX trazem consigo novas representações de constrangimentos morais, e outros ideais substituem a culpabilidade como organizadora da economia psíquica. A autoafirmação dos indivíduos ganha preeminência enquanto valor e se torna uma condição normativa. Com a redução de um estado coercitivo, aumenta a introjeção do controle de si. O transtorno obsessivo-compulsivo, diferentemente da neurose obsessiva, seria, assim, uma doença do escrúpulo, e não da dúvida, sendo as ameaças sentidas mais de dentro de si mesmo do que de fora, do espaço social. Corrobora, assim, o que Gori (2010), em acordo com Hacking, chama a atenção quando fala das psicopatologias "enquanto reveladoras da substância ética da cultura da qual elas emergem e que elas contribuem, em retorno, para recodificar" (Gori, 2010, p.6).

De uma outra perspectiva, Lane (2006) vai analisar a patologização crescente de comportamentos humanos antes tidos como diferentes, porém normais e anódinos. Associa a criação de novas patologias a interesses mercadológicos das indústrias farmacêuticas, que dão sustentação a associações em torno dessas patologias e se aliam a grupos de psiquatras, investindo somas estratosféricas no marketing das mesmas. Baseado na virada biológica da psiquiatria, que explica comportamentos patológicos a partir de disfunções cerebrais, verifica-se o crescimento exponencial de comportamentos tornados anormais e categorizados nas nosologias dos DSM, para os quais progressivas descobertas psicofarmacológicas aportariam um tratamento. Esse é, para o autor, o solo social e econômico-científico da transformação, por exemplo, da timidez em fobia social. Surge uma tendência à intolerância aos introvertidos, misantropos, pessimistas, entre outros personagens que povoavam as sociedades, fazendo parte das múltiplas formas de subjetividade humana. Esta intolerância e a patologização destes comportamentos seriam o resultado, segundo o autor, de uma fantasia de que, desenhando o nosso próprio cérebro, seremos capazes de calibrá-lo. Lane (2006, p.408) prossegue afirmando que «[a] psicofarmacologia transforma essa fantasia em uma demanda ética», quando concebe esses 'transtornos psiquiátricos' como problemas da vida humana que as drogas podem eliminar.

As análises empreendidas por esses autores favorecem a apreensão da atmosfera cultural e do ar do tempo que matizam a experiência coletiva de mal-estares e formas de sofrimento a partir de um campo semântico e pragmático que as circunscreve. Como campo semântico e pragmático, entendemos um conjunto de valores, símbolos, construções de pessoa e modos de fazer compartilhados e produzidos em contextos sociais definidos a partir de uma conjuntura histórica, que envolve relações de poder e econômicas, semelhante ao que Foucault chama de dispositivos ou práticas discursivas. Nesse caso, sintomas e patologias subscrevem valores morais e se situam em relações sociais concretas, refletindo e participando dos jogos de posicionamento social e sofrendo os efeitos dos seus conflitos e dinâmicas sociais. 


\section{Categorias diagnósticas: as tramas antropológicas das suas estandardizações e o manejo do social nas geografias clínicas}

A relevância do diagnóstico psiquiátrico é um tema extremamente debatido em vários dos seus aspectos: social, pela relação que ele estabelece com a rotulação e a estigmatização das pessoas; clínico, na definição de quadros nosológicos e no que diz respeito às informações relevantes que ele aporta para um tratamento mais eficaz; na pesquisa, no que tange à capacidade de comparar taxas de prevalência de doenças mentais em diferentes países. Menos comum, no entanto, é a problematização dos processos científicos de definição e estandardização desses diagnósticos em suas interfaces com situações sociais concretas. Alguns estudos etnográficos têm se debruçado sobre as neurociências, tanto nos seus processos de descoberta de novas patologias quanto na definição dos seus mecanismos neurobiológicos e genéticos. Esses estudos têm sido importantes ao exporem as malhas pelas quais o biopoder se manifesta. Evidenciam, por outro lado, as formas de negociação social ou entre tradições culturais pelas quais os regimes de verdade são desafiados.

Como representante desse grupo de estudos, temos Andrew Lakoff (2005), que se interessa pelo modo como se produzem regimes de estandardização e técnicas transnacionais de regulação de diagnósticos em psiquiatria. Com esse propósito, vai estudar a cooperação científica estabelecida entre uma companhia biotecnológica francesa e uma instituição psiquiátrica argentina que visam a desenvolver um projeto de identificação e patenteamento de genes humanos ligados aos transtornos afetivos bipolares. O autor desenvolve o artigo em torno de temas relacionados à consistência diagnóstica em psiquiatria. Descreve a fragilidade da construção diagnóstica advinda de consultas rápidas, pautadas em protocolos de pesquisa predefinidos. Apresenta o problema conceitual ligado ao reconhecimento do fenótipo de doenças mentais, de cuja definição dependem acordos de que amostras genéticas seriam tiradas de pessoas com um mesmo diagnóstico. Esse aspecto torna-se delicado quando se analisam as doenças mentais historicamente e se observam as variações nas fronteiras que as distinguem entre si. Estas variações teriam um impacto desfavorável na definição de genótipos e de gens dominantes para tipos específicos de doenças. A questão sobre o grau de equivalência entre doenças mentais e somáticas estaria ligada ao modo pelo qual a psiquiatria conseguiria estabilizar os seus objetos, evidenciando múltiplos elementos em jogo. Estandardizar critérios envolve a capacidade da psiquiatria de produzir e difundir artefatos que transcendam condições locais, tais como os manuais diagnósticos, tornando comportamentos patológicos globalmente transferíveis. Além disso, implicariam a definição nacional de normas administrativas que adotem e tornem hegemônicos esses artefatos, tornando-os necessários a fins diversos, dentre os quais os protocolos de seguros e benefícios. Contraditoriamente, segundo o autor, a ecologia da expertise local pode estar (como na Argentina, especialmente pela forte presença da tradição psicanalítica) pautada na resistência a esses critérios, na suspeição dos diagnósticos e em elementos de prestígio profissional diferentes daqueles ancorados na publicação de artigos científicos de base universal.

Lakoff conclui evidenciando que as condições locais, de um contexto nacional específico, aportam camadas de complexidade para o debate que precedem as descobertas genéticas e que envolvem o diagnóstico. Elas colocam em movimento, de um lado, relações entre ciência, indústria e administração da saúde, veiculando o que o autor chama de liquidez diagnóstica (sua transferabilidade); de outro lado, uma cultura profissional, com suas bases epistemológicas, além dos modos de autoidentificação de sujeitos em torno de uma determinada doença. Para o autor, ainda que a circulação científica de informações do domínio da genômica seja um aspecto-chave para a sua estandardização, ela, por si só, não garante a transformação da identidade do paciente nem a estabilização da doença.

As evidências apresentadas por Lakoff, através da desconstrução do processo pelo qual pesquisas científicas são realizadas, permitem confrontar a naturalização com a qual resultados de pesquisas neurobiológicas são expostos e antecipados. Outros estudos têm se dedicado a compreender os usos clínicos dos diagnósticos e dos tratamentos psiquiátricos, seus efeitos e devires sociais para além do cientificamente previsto. 
Jupille (2011), estudando o tratamento de crianças com transtorno da atenção com ou sem hiperatividade (TDAH), em um serviço universitário de orientação cognitivista em Paris, observa que estabelecer um diagnóstico é fruto de um processo de negociações estabelecido entre vários atores (professores, pais, profissionais, laboratórios). Alguns desses atores apresentam representações divergentes quanto à doença, reflexo de controvérsias na sociedade mais vasta. Jupille descreve o alívio das famílias quando recebem uma explicação neurobiológica para o transtorno e tratamento medicamentoso e psicoeducativo, buscadas através de demandas estereotipadas em fórmulas que agregam os sintomas mais importantes da doença, dirigidas às instituições de cuidado. A despeito dessa unificação da diversidade pelo diagnóstico, o autor observa que o curso do tratamento individualiza as queixas e permite singularizar as situações das famílias. Observa que a satisfação com o medicamento (metilfenidato) é transitória, o que exige permanentes reajustes da sua dose, refletindo o processo de individualização do cuidado. O autor conclui que o papel do medicamento é o de servir como um articulador central das relações socioafetivas que passam a se estabelecer entre os membros das famílias que possuem um(a) filho(a) com esse diagnóstico, produzindo um trabalho sobre a relação, mudando o cotidiano dos mesmos e melhorando a reinserção social das crianças. Por sua vez, as mudanças propiciadas pelo diagnóstico dependem, de um lado, dos acordos, ou desacordos, produzidos pelas formas de dar sentido às dificuldades da criança e, de outro, das táticas de homologação desenvolvidas pelos pais com a ajuda dos técnicos. Esse estudo permite entender que o resultado dessa abordagem clínica é altamente dependente da lógica social das relações, estando muito distante das assertivas essencialmente naturalistas propostas pela neurobiologia quando se refere ao efeito das medicações sobre o controle de comportamentos disfuncionais.

A incorporação do social por psiquiatras, no manejo do diagnóstico, é proposta, de modo ainda mais contundente, por Béhague (2009). Seu estudo, realizado no âmbito da clínica psiquiátrica voltada para adolescentes de Pelotas, Brasil, oferece insights acerca da correlação entre o discurso, a prática biopsiquiátrica e seus processos psicossociais. Na parte qualitativa desse estudo, a autora acompanha, durante nove anos, um grupo de adolescentes, com diagnóstico de problemas de conduta, tratados psicoterapeuticamente por psiquiatras em serviços públicos de saúde mental dessa cidade. Busca, entre outros objetivos, discutir a modalidade e o processo de biomedicalização dessa sociedade. Para isso enfoca o aparente paradoxo entre uma psiquiatria que realiza tantos diagnósticos pautados em definições comportamentais (revelado por dados epidemiológicos do mesmo estudo, que mostram um crescimento desses diagnósticos prioritariamente atribuídos a crianças de baixa renda e a jovens do sexo masculino) e uma clínica psicoterapêutica socialmente orientada. O argumento principal da autora se constrói a partir da análise de casos bem-sucedidos de acompanhamento terapêutico, onde as respostas favoráveis dos adolescentes resultaram de uma relação terapêutica centrada na elaboração (psíquica) dos determinante sociais à base dos seus comportamentos, a partir de uma perspectiva terapêutica politizadora. Descrevendo essas terapêuticas, o(a)s jovens evidenciavam um aumento do seu poder de análise dos conflitos da sociedade onde viviam, observando a relação entre suas dificuldades pessoais e os sentimentos que experimentavam quanto às injustiças sociais. Além disso, produziram formas mais legítimas de rejeição às mesmas, tais como o ativismo político, ou outras formas de empoderamento. $O$ resultado, segundo a autora, é uma transformação psi-induzida, onde se produz um deslocamento de uma perspectiva individualizada para outra mais coletiva, acompanhada de mudanças pessoais e estruturais na experiência dos jovens. Na análise de Béhague, esse tipo de terapia encontra-se fortemente enraizado em práticas psiquiátricas política e socialmente sensíveis, fruto de um pensamento desenvolvido a partir de contradiscursos nascidos dos movimentos antipsiquiátricos, no processo da reforma psiquiátrica brasileira. A autora evidencia que profissionais sensíveis às condições sociais nas quais se produzem sofrimentos humanos têm a capacidade de se distanciar do aspecto categorizador dos diagnósticos para fazer emergir as lógicas sociais subjacentes ao mal-estar dos sujeitos.

Categorias diagnósticas podem ser também consideradas como pré-textos para comunicar problemas e produzir significados, os quais são fortemente dependentes dos espaços materiais e sociais nos quais eles ganham forma. Das e Das (2007) sugerem que os estudos sobre os significados das doenças têm dado pouca atenção à especificidade das condições sociais nas quais as pessoas experimentam a saúde e a doença. Esse aspecto pode ser explorado no campo da saúde mental, observando-se em que medida 
condições de pobreza, marginalidade e desigualdade social encontram eco nas formas pelas quais os terapeutas, mas também os doentes, manejam diagnósticos psiquiátricos. As autoras evidenciam a precariedade da vida cotidiana de certos bairros populares como um complexo que constitui uma ecologia local que engloba circunstâncias políticas e econômicas colocadas em jogo no momento de circulação e de manipulação de diagnósticos, bem como nos sentidos que eles favorecem a elaboração.

Em contextos marginais ao próprio enquadramento psiquiátrico, esses usos podem também ser observados. Um bom exemplo é o trabalho de Lovell (2001) que estuda moradores das ruas de Nova York com delírios identificatórios, evidenciando como esses sintomas mentais canalizam imperativos morais e conteúdos identitários sustentados por uma lógica social. A autora descreve a significação social da vida na rua, problematizando a relevância da identidade social em um tal contexto, que a faz adquirir uma qualidade de mediadora das interações sociais. Viver na rua exige o domínio de um verdadeiro teatro de apresentação de si, o que envolve corpo, gestos e palavras na modelagem dos seus contornos identitários. Segundo Lovell, esse trabalho de identificação ganha maior importância quando os sem domicílio são percebidos como «loucos» (Lovell, 2001, p.132). A versão delirante da fabricação de si ocupa, aqui, um lugar fundamental, cujo aspecto fictício é facilitado pelos espaços intersticiais da rua. Esses delírios parecem repousar em situações relacionais, influenciadas por pertencimento étnico ou de gênero, funcionando como estratégia para embelezar o passado de pessoas que romperam seus laços familiares. Diferentemente de diagnósticos comparáveis na psiquiatria, tais como as síndrome de Capgras ou de Fregoli, os delírios da rua parecem mais afeitos a mecanismos de sobrevivência em face da aniquilação social, colocando em jogo questões de racismo envolvidas nos pertencimentos étnicos. Delírios desse tipo são inteligíveis à luz da experiência de discriminação, evidenciam um mecanismo de inversão diante do sentimento de desrespeito, fazendo apelo a um registro de justificação em uma sociedade de direitos e de cidadania. Essas ficções de si funcionam em uma lógica social de comunicação com os outros, uma forma de produção de rede social (verdadeira ou não), enfatizando modelos transacionais.

As situações sociais e contextos econômicos de inscrição também influenciam posturas profissionais na utilização e avaliação dos novos recursos etiológicos, diagnósticos e terapêuticos definidos pela biopsiquiatria. Muitas vezes, fascinados pelas promessas anunciadas pelas descobertas científicas e pelas novas tecnologias colocadas à disposição de sociedades de capitalismo avançado, os pesquisadores se esquecem que um sem número de países, ainda que expostos aos regimes de verdade neurobiológicos e às redes de influência das indústrias farmacêuticas, estão à margem do acesso às mesmas.

Good (2007), em estudo realizado em Java, Indonésia, verifica, na psiquiatria javanesa, a influência de um projeto de essencialização biológica da doença mental, interpretando-o a partir dos avanços na síntese de novos psicofármacos mais eficazes, aliados aos interesses de ampliação de mercados de medicamentos e de biotecnologia, ao que se associa a vontade do país de desenvolver seu projeto de modernidade. Esse projeto, no entanto, encontra inúmeros obstáculos, diretamente sentidos na prática psiquiátrica, onde um contexto de baixa renda impossibilita o real acesso aos avanços oferecidos pela psiquiatria contemporânea, gerando um sentimento de inadequação. Além disso, os psiquiatras javaneses, segundo Good, não pareciam completamente convertidos a esse projeto e se ressentiam da progressiva racionalização e desencantamento do mundo e dos processos de cura. Alguns destes se diziam capazes de distinguir doenças de causa biológica daquelas de origem espiritual, dentre os quais existiam aqueles que associavam dois tipos de prática: psiquiatria moderna e terapêutica tradicional. Essa soma de precariedade econômica e de valores tradicionais em certas sociedades é importante no incompleto sucesso e complexa configuração do projeto de biossocialidade dos sujeitos nesses contextos.

As descrições antropológicas das formas pelas quais essa densa textura do social interage com sintomas psiquiátricos informam acerca da inelutável constituição multifatorial das doenças mentais: na construção histórica do normal e do patológico; nas condições materiais da sua experiência e consequente incorporação das mesmas nos seus sintomas, ou no desvendamento da sua compreensão; na recuperação dos recursos biológicos na (re)tessitura de laços sociais; nos interesses socioeconômicos em jogo na economia das terapêuticas e da produção das doenças. No próximo grupo de estudos, vamos deslocar o foco dos recursos psiquiátricos e seus usos para os recursos socioculturais, naquilo que 
eles oferecem de permeabilidade social às experiências de alteridade vividas por pessoas com diagnósticos de psicose, ou ainda nas formas singulares pelas quais as pessoas jogam com os mesmos para conviver, comunicar e socializar a sua diferença.

\section{Subjetividades recessivas:}

\section{a elaboração e comunicação dos sentidos da loucura pelo trabalho da cultura}

A cultura psiquiátrica moderna, tendo em vista a sua hegemonia epistemológica e tecnológica, quase inevitavelmente, atravessa os vários campos da saúde e da doença mental; do mesmo modo, o social a ressignifica e modifica. Observam-se que outras dimensões da cultura, tais como o domínio da espiritualidade, da arte etc., também participam da articulação e significação das experiências de alteridade, fazendo parte do que Obeyesekere (1990) chama do trabalho da cultura na elaboração das experiências coletivas e pessoais, em analogia ao que Freud chamou do trabalho do inconsciente na elaboração das questões psíquicas.

Uma parte desse trabalho se realiza através do que Corin (2007) identifica como dimensões culturais estruturantes, que inscrevem e contêm tensões que vão orientar o jogo social em relação às suas alteridades, dentre as quais a loucura, favorecendo ou dificultando o seu lugar social. Outra parte, não menos relevante desse trabalho, se realiza através dos múltiplos jogos subjetivos de utilização dos recursos culturais, complexificando e modificando essas relações dinâmicas com a alteridade. Assim, por exemplo, experiências de um mesmo diagnóstico psiquiátrico podem ser vividas de modo diferente em função dos contextos nos quais esse trabalho da cultura se realiza e dos usos da cultura na articulação dessas experiências. $O$ estudo de alguns desses aspectos tem evidenciado a possibilidade que eles abrem a uma posição de maior compreensão, comunicação, respeito, ou acolhimento da diferença. Esses estudos reposicionam sintomas como dimensões da experiência subjetiva e social, restituindo-lhes a possibilidade de fazerem sentido dentro de uma lógica relacional e humana.

A partir de estudo realizado em Montreal, Corin e Lauzon (1992) observam que os esquizofrênicos menos frequentemente hospitalizados, pareados por idade e gravidade da doença com os mais hospitalizados, eram aqueles que tendiam a positivar o seu modo mais isolado de estar no mundo. Corin denomina essa experiência de retraimento positivo (retrait positif), usando esse conceito para dialogar com um clássico sintoma negativo da esquizofrenia - o retraimento ou isolamento. Essa positivação poderia se dar: pela valorização de estados de isolamento como formas de marcar uma diferença concebida como positiva; pela mediação estabelecida com as suas relações sociais ou no desempenho dos seus papéis sociais. Para isso, essas pessoas colocavam em ação formas muito particulares de reinterpretação idiossincrática de recursos culturais, de bricolagem com os significantes religiosos, de escolha de espaços mais sintônicos com sua percepção subjetiva do mundo e de jogos relacionais onde uma aproximação distanciada era habilmente construída de modo a garantir para si "um espaço pessoal de proteção às margens do mundo ordinário 'normal' " (Corin, Lauzon, 1992, p.280).

Com base em suas investigações na Índia, Corin (2007) complexifica seu quadro conceitual, interessando-se por aspectos estruturantes da cultura que favoreceriam modos de subjetivação dessa ex-centricidade do sujeito. Comparando as experiências dos psicóticos e de seus familiares nesse país, a autora verifica que, se ambos recorriam bastante à religião para lidar com a experiência da esquizofrenia, os primeiros, no entanto, não recorriam aos mesmos significantes religiosos nem os interpretavam da mesma forma que os segundos. Enquanto os pacientes os usavam de modo a tentar nomear, domesticar e, de certo modo, integrar um penetrante sentido de estranheza; " [e assim] deixar a estranheza intacta - e possivelmente até a protege[r]"; do seu lado, os familiares "tentavam apagar e diminuir a esquisitice do comportamento dos pacientes e integrá-los em um quadro coletivo e culturalmente texturizado" (Corin, 2007, p.299, minha tradução).

Corin conclui dizendo que essas discrepâncias remetem a uma heterogeneidade presente na própria cultura indiana. Esta diz respeito à religião hinduísta, na qual se observa uma tensão entre ritual e adoração, de um lado, e práticas ascéticas e iluminação, de outro (Madan, 1987 apud Corin, 2007). As primeiras, consideradas importantes no cumprimento das tarefas no mundo, de acordo com a noção de dharma, estariam mais próximas dos usos que os familiares faziam da religião; enquanto as últimas, 
extremamente valorizadas na renúncia dos sadhus, sendo considerada o apogeu da vida, estariam mais condizentes com os modos pelos quais os pacientes situavam sua experiência de alteridade. Para Corin (2007), essa heterogeneidade estrutural no interior da cultura abre espaço para que as pessoas joguem com a mesma na perspectiva de construírem trajetórias próprias e, no caso dos psicóticos, explorarem e conterem seus sentidos de estranhamento e articularem um espaço de diferença. Como hipótese, ela sugere que esses jogos teriam um efeito favorável na evolução da doença, uma das razões pelas quais o prognóstico da esquizofrenia seria melhor na Índia quando comparado com os Estados Unidos, como encontrado por Sartorius (1986).

Em pesquisa realizada em Cachoeira, Bahia (Nunes, 1999), foi observado que a existência e a utilização do idioma do Candomblé por pessoas psicóticas também eram uma forma importante de lidar com a experiência de alteridade e abria canais de relação com a comunidade, favorecendo uma inserção social, ainda que paradoxal. Além do aspecto de comunicação, o que pareceu mais estruturante e protetor na utilização dos recursos dessa religião foi a sua utilização idiossincrática pelas pessoas psicóticas, de modo a dialogarem com o estranhamento da experiência, o que foi denominado de reescrita do idioma religioso.

Essa reescrita dizia respeito ao fato de que as pessoas psicóticas estudadas, apesar de resistirem a um enquadramento religioso enquanto adeptas e a despeito de confessarem um estranhamento acerca do saber fazer do candomblé, desenvolviam formas singulares de utilizá-lo na sua vida cotidiana. Essas utilizações ajudavam-nas a criar relações privilegiadas e diretas com divindades do candomblé, não mediadas pela intervenção de líderes religiosos, nem pelas obrigações rituais tradicionais. Ao contrário, estas eram criadas pela bricolagem desses saberes tradicionais com interpretações próprias, muitas vezes ligadas a um imaginário psicótico, envolvendo ideias de perseguição, de grandeza ou de poderes extraordinários. Outra utilização importante era a de nomear ou significar experiências estranhas e ameaçadoras a partir de explicações religiosas, tais como: escutar vozes malignas como sendo a voz de Exu; ler o pensamento dos outros como uma habilidade de um médium de audição; sentir algo controlando a sua voz como a influência de Preto Velho; apresentar visões de animais peçonhentos como sinal mágico; ou apresentar alterações sensoriais olfativas, o cheiro de coisas em putrefação, como indicação de que algum feitiço tinha sido enviado para lhe fazer um mal. Outros usos seriam aqueles situados a meio caminho entre um saber fazer tradicional e um arranjo 'estranho'. Como exemplos desse arranjo, observaram-se: a utilização de folhas de mariô, à moda de terreiros de candomblé, na entrada da casa, como uma proteção contra a invasão de males invisíveis; a utilização de flores e de garrafas de bebida, retiradas do lixo, para uma oferenda a Janaína; a receita com pimenta da costa para esquentar a cabeça daquele que detém a guarda de um filho, perdida sob determinação judiciária, para assim fazê-lo voltar. Todos esses usos, encontrados entre as mulheres estudadas, mantinham-nas, paradoxalmente, em contato e em interlocução com seus vizinhos e parentes. Entendidos como bizarrices de quem tinha o ori (cabeça) fraco, esses usos permitiam-Ihes, contudo, tornar menos aterrorizadores pensamentos intrusivos, tornar mais sagrados e nobres comportamentos impertinentes e atribuir poder a discursos exaltados.

Outros resultados etnográficos que este estudo aporta são as convergências entre as utilizações idiossincráticas de uma cultura pelas pessoas doentes e as brechas coletivamente construídas dessa malha cultural que possibilitam a não-rejeição desses sujeitos. Entre essas importantes construções culturais, destacam-se as sutis possibilidades de resgate de histórias que derraparam dessa trama simbólica, condensadas no conceito de resgate transgeracional da desordem. Por este conceito, o candomblé operaria a partir de uma lógica onde um indivíduo doente é imediatamente inscrito em uma trama social de formato intergeracional. Neste, uma pessoa de segunda ou, principalmente, terceira geração pode resgatar a desordem que caiu sobre os ombros de um dos membros antecessores da sua família, abrindo-Ihe a possibilidade de resgatar certa ordem, ou reposicionamento, no mundo social e físico. Para isso, o membro dessa geração sucessora deve reparar o mal, realizando, ele mesmo, os rituais ou cuidados espirituais transgredidos pelo seu familiar. Esse conceito é fortalecido por um outro, a recessividade social da doença, proposto por Zempléni (1977), que informa essa condição não atomizada, ou coletiva, do adoecer, que implica necessariamente outros no reordenamento do mal, incluindo uma série de reorientações sociais e relacionais para além dos atos simbólicos. 
O resgate transgeracional da desordem foi, entre outros, um dos aspectos estruturantes do candomblé de Cachoeira, que surgiu como recurso utilizado por algumas pessoas para imaginarem um futuro mais alvissareiro para certos domínios coercitivos da loucura, inclusive o de ser colocado à margem dos laços familiares. Através dele, uma mulher readquire a chance de ter sua neta iniciando-se nos rituais em que ela, num momento frágil da sua história, não pôde se engajar (Nunes, 2000). Outra, por sua vez, compreende sua 'crise de loucura' como o chamado de um orixá para reparar o curso desviante de sua família em relação a obrigações rituais diante de uma divindade. Esses aspectos remetem a uma psicologia cultural local (Good, 2007), que oferece recursos mais favoráveis ao acolhimento ou ao manejo de certos aspectos da estranheza da experiência psicótica, ou da sua diferença.

\section{Conclusão}

As interseções pelas quais tentamos conduzir o leitor neste artigo, situadas entre história, cultura, sociedade e biologia, buscam traduzir a doença mental nos seus nós, dificilmente desatáveis. Elas surgem como os contornos destacados de uma paisagem, de modo a fazer ressaltar, sucessivamente, um ou outro elemento, à moda de uma gestalt. Em certos momentos, o que sobressai são as explicações neurobiológicas, que vêm aliviar fardos e sentimentos de culpa; em outras ocasiões, são as tradições culturais que, na vida concreta de muitas pessoas, vão nuançar os males psiquiátricos, tornando sintomas 'hard' mais leves e fáceis de dominar.

Onde quer que se situem, na perspectiva de um corpo biológico, ou naquela de um corpo social, as várias dimensões da experiência humana realizam interseções na tentativa de produzirem significados. Esta produção não é espúria ou periférica; ela constitui os fenômenos, atribuindo-Ihes densidade. Para compreendê-la, escolhas analíticas são feitas de forma a ultrapassar a armadilha de dispor, de modo apenas sobreposto, as camadas que compõem a existência individual ou coletiva por cujas articulações a experiência do adoecimento se efetua. Este artigo colocou, portanto, como objetivo examinar algumas dessas análises, finamente construídas a partir de diferentes aportes teórico-metodológicos, nas suas evidências empíricas das formas pelas quais se modela a espessura biopsicossociocultural do adoecimento mental.

Nesse adensamento, vimos que as polaridades culturais do vício e da virtude podem, como diz Hacking (1998), inscrever as doenças nos seus nichos ecológicos, e essa inscrição pode favorecer a positivação de experiências dolorosas, pela situação do patológico em um continuum mais alvissareiro com os excessos do normal. A compreensão desses nichos ecológicos permite, talvez, aos que sofrem desses males, não estarem sozinhos no desvio da rota, mas perceberem os movimentos do coletivo envolvidos na modulação dos desvirtuamentos de um tempo. Esse movimento pode remeter ao conceito etnográfico de Zempléni, a recessividade social das doenças, mais evidenciado, segundo o autor, em sociedades predominantemente sociocêntricas, onde os males não são apenas de responsabilidade individual ou resultado de heranças genéticas deterministas, mas, necessariamente, envolvem os grupos no seu enlace e desenlace. Na saúde coletiva, isso se aproximaria do conceito de consciência sanitária, tendo este último um sentido maior de positividade e sendo fruto de uma produção mais induzida sobre os grupos do que de uma vivência socialmente incorporada, como os anteriores.

Nessa paisagem da saúde mental, observam-se ainda que as tramas do social atualizam as tecnologias e incorporam-nas nas suas formas de produzir lógica, o que a clínica evidencia amplamente, revelando o senso prático da ciência. Daí que os discursos dos progressos científicos estejam sempre um tanto descompassados em relação aos seus efeitos sociais. A não ser que esses efeitos sejam entendidos como os de uma ideologia favorável aos mesmos pela produção de mentalidades mais receptivas e consumidoras de tecnologias e medicamentos, o que justifica tanto investimento midiático e publicitário em novas descobertas.

Quanto a isso, Bourdieu (2003) chama a atenção para o fato de que uma determinada ordem social pode ganhar eficácia pelo fato de apoiar-se sobre uma relação de dominação inscrita em uma biologia, 
que é, ela mesma, uma construção social biologizada. A configuração de universalidade de certos ordenamentos, que se impõem como autoevidentes e universais, ganhando ares de uma profunda necessidade, pode dissimular possibilidades que escapariam, assim, do reconhecimento da falta de justificativa. Tal como sugerido por Hoy (1999), a própria biologia, quando colocada para uso social, se torna uma categoria socialmente construída, que pode servir para construir possibilidades sociais. Assim, notam-se: mudanças expressivas nas nosologias psiquiátricas contemporâneas, um aumento exponencial de pessoas diagnosticadas com novas patologias e um avassalador consumo de novas drogas. No entanto, modulando a pretensão universalista à base desses saberes, observam-se os contornos locais dessas mudanças, as formas de resistência às mesmas, e as refrações nos seus usos e significados evidenciam o que chamamos de geografias clínicas.

O que se vê é que as intempéries e vicissitudes da vida concreta dos sujeitos servem de bússola a partir das quais as pessoas lançam mão dos recursos disponíveis para desatarem os nós que tensionam as relações humanas nas quais estão inseridas. Produzem-se o que chamamos das subjetividades socialmente recessivas, que elaboram e comunicam os sentidos das experiências de sofrimento psíquico pelas dobradiças do trabalho da cultura. A disponibilidade de recursos culturais, no entanto, não é assim tão uniforme, nem são da mesma natureza de uma sociedade a outra. Os usos desses recursos aparecem como formas de nomear, significar, tratar e negociar com os vários sofrimentos da alma, e tendem a problematizar os regimes de verdade naturalistas. Como diz Hoy (1999, p.7, minha tradução): «o ponto é que a invariância não precisa ser completamente negada, mas a real universalidade dessas invariantes pode ser tão diluída a ponto de torná-las desinteressantes, ou rasa demais para responder às mais interessantes e críticas questões» acerca das complexas experiências de pessoas que vivenciam sofrimentos psíquicos.

\section{Referências}

BÉHAGUE, D.P. Psychiatry and politics in Pelotas, Brazil: the equivocal quality of conduct disorder and related diagnoses. Med. Anthropol.Q., v.23, n.4, p.455-82, 2009.

BOURDIEU, P. A dominação masculina. Rio de Janeiro: Bertrand Brasil, 2003.

CASTEL, P.H. De la névrose obsessionnelle aux TOC: remarques sur le passage du paradigme psychanalytique au paradigme cognitivo-comportamentaliste. In: CHAMPION, F. (Org.) Les psychothérapies aujourd'hui. Paris: Armand Colin, 2008. p.186-202.

CORIN, E. The other of culture in psychosis: the ex-centricity of the subject. In: BIEHL, J.; GOOD, B.; KLEINMAN, A. (Orgs.). Subjectivity: ethnographic investigations. Berkeley: University of California Press, 2007. p.273-314.

CORIN, E.; LAUZON, G. Positive withdrawal and the quest for meaning: the reconstruction of experience among schizophrenics. Psychiatry, v.55, n.3, p.266-78, 1992.

DAS, V.; DAS, R.K. How the body speaks: illness and the lifeworld among the urban poor. In: BIEHL, J.; GOOD, B.; KLEINMAN, A. (Orgs.). Subjectivity: ethnographic investigations. Berkeley: University of California Press, 2007. p.66-97.

DAVIS, L.J. Obsession: a history. Chicago: University of Chicago Press, 2008.

EHRENBERG, A.; LOVELL, A.M. Pourquoi avons-nous besoin d'une reflexion sur la psychiatrie? In: (Orgs.). La maladie mentale en mutation: psychiatrie et société. Paris: Odile Jacob, 2001. p.9-42. 
GOOD, B. The subject of mental illness: psychosis, mad violence, and subjectivity in Indonesia. In: BIEHL, J.; GOOD, B.; KLEINMAN, A. (Orgs.). Subjectivity: ethnographic investigations. Berkeley: University of California Press, 2007. p.243-72.

GORI, R. As patologias do niilismo em nossa modernidade. Tempo Psicanal., v.42, n.1, p.107-29, 2010.

HACKING, I. Mad travelers: reflections on the reality of transient mental illnesses. Charlottesville: University Press of Virginia, 1998.

HOY, D.C. Critical resistance: Foucault and Bourdieu. In: WEISS, G.; HABER, H.F. (Orgs.). Perspectives on embodiment: the intersections of nature and culture. New York: Routledge, 1999. p.3-22.

JEANNEROD, M. Y a-t-il des limites à la naturalisation des états mentaux? In: EHRENBERG, A.; LOVELL, A.M. (Orgs.). La maladie mentale en mutation: psychiatrie et société. Paris: Odile Jacob, 2001. p.266-78.

JUPILLE, J. L'hyperactivité infantile: une enquête de sociologie empirique: "Certains naissent gauchers, et bien toi, tu es hyperactif". 2011. Tese (Doutorado) - Université Paris V, Descartes, Paris. 2011.

LAKOFF, A. Diagnostic liquidity: Mental illness and the global trade in DNA. Theor. Soc., v.34, p.63-92, 2005.

LANE, C. How shyness became an illness: a brief history of social phobia. Common Knowl., v.12, n.3, p.388-406, 2006.

LOVELL, A.M. Les fictions de soi-même ou les délires identificatoires dans la rue. In: EHRENBERG, A.; LOVELL, A.M. (Orgs.). La maladie mentale en mutation: psychiatrie et société. Paris: Odile Jacob, 2001. p.127-62.

MADAN, T.N. Non-renunciation: themes and interpretation of Hindu culture. Dehli: Oxford University Press, 1987.

NUNES, M.O. À temps et à contre-temps: les voix des tambours dans l'expérience des psychotiques. 1999. Tese (Doutorado) - Département d'Anthropologie, Université de Montréal, Montreal. 1999.

. Les liens de saint et de sang: Candomblé et réaménagement du désordre

familial. Cah. Anthropol. (Montreal), v.3, p.47-56, 2000.

OBEYESEKERE, G. The work of culture: transformation in psychoanalysis and anthropology. Chicago: University of Chicago Press, 1990.

SARTORIUS, N. et al. Early manifestations and first-contact incidence of schizophrenia in different cultures: a preliminary report on the initial evaluation phase of the WHO collaborative study on determinants of outcome of severe mental disorders. Psychol. Med., v.16, n.4, p.909-28,1986.

YOUNG, A. Nos névroses traumatiques ont-elles un avenir? In: EHRENBERG, A.; LOVELL, A.M. (Orgs.). La maladie mentale en mutation: psychiatrie et société. Paris: Odile Jacob, 2001. p.101-26.

ZEMPLÉNI, A. From symptom to sacrifice: the story of Khadi Fall. In: CRAPANZANO, V.; GARRISON, V. (Orgs.). Case studies in spirit possession. New York: John Wiley \& Sons, 1977. p.87-139. 
NUNES, M.O. Intersecciones antropológicas en salud mental: de los regimenes de verdad naturalistas a la densidad bio-psico-sociocultural de la enfermedad mental. Interface - Comunic., Saude, Educ., v.16, n.43, p.903-15, out./dez. 2012.

En la psiquiatría contemporánea, un proyecto hegemónico trans-nacional centrado sobre un discurso naturalista acerca de las enfermedades mentales propaga un régimen de verdad anclado en la propuesta de explicación de su fisiopatología y en el dominio de su tratamiento. A pesar de su gran difusión, un grupo de estudios demuestra como ese discurso repercute de forma diferente en contextos culturales específicos. Un segundo grupo analiza las construcciones históricas de las enfermedades mentales, definiendo polaridades culturales que valorizan como virtuosos o viciosos determinados comportamientos. Un tercer grupo analiza los usos de recursos culturales como un modo de negociar experiencias de alteridad, produciendo contextos más abiertos a la diferencia. Este artículo es una revisión de esas perspectivas, destacando intersecciones entre historia, cultura, sociedad y biología en la base de las enfermedades mentales.

Palabras clave: Antropología médica. Enfermedad mental. Utilización de medicamentos. Construcción social. Alteridad. 


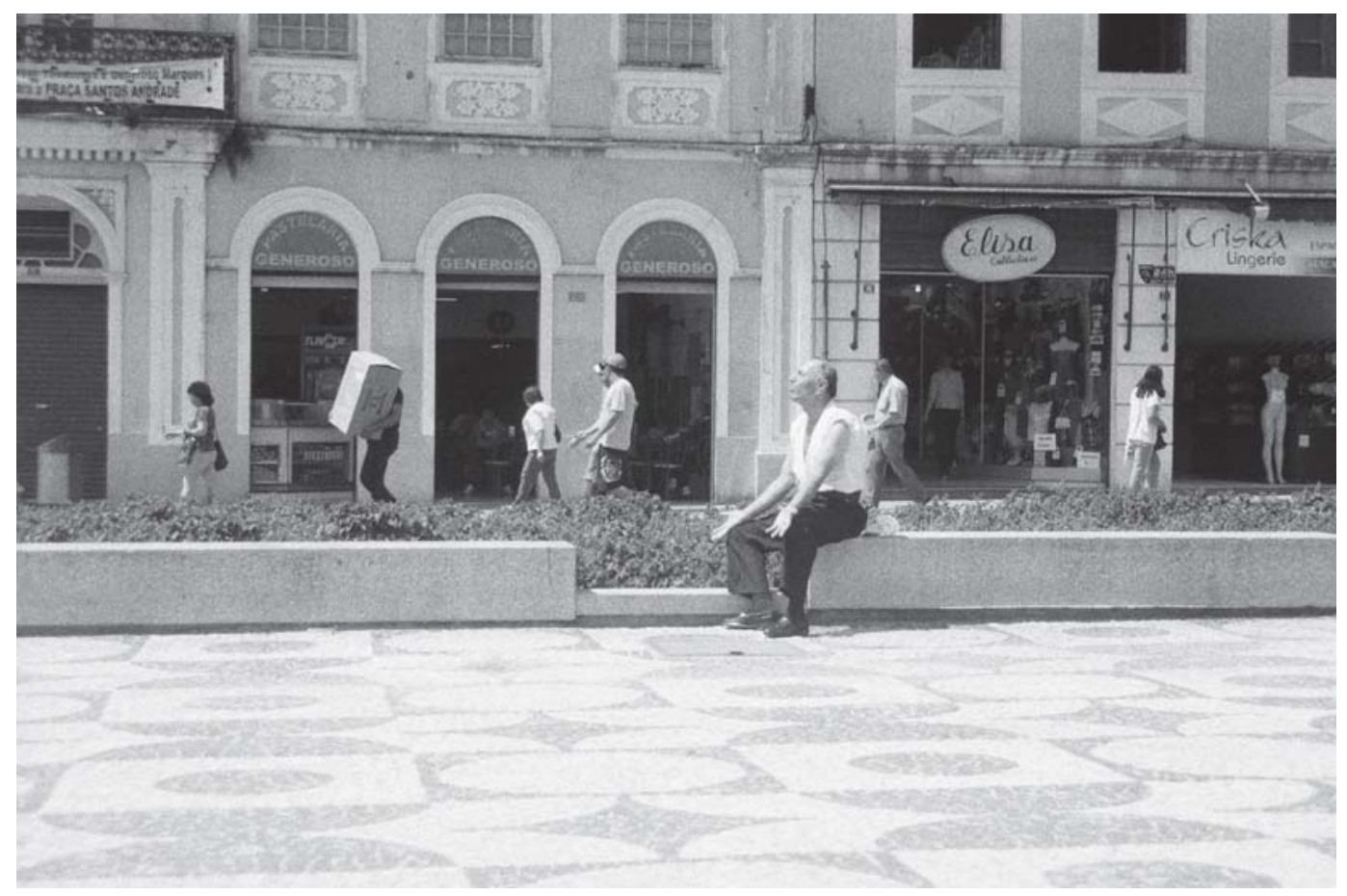

Ricardo Pozzo, Projeto Urbe fágica, 2012 